\title{
A Case of Adrenal Myelolipoma Associated with Hereditary Spherocytosis
}

\author{
Dahui Gug${ }^{1}$, Ha Young Park ${ }^{2}$, Bo Lyun Lee ${ }^{1}$, Kwang Hoon Kim', Jeong Eun Lee ${ }^{1}$ and Ji Kyoung Park \\ Departments of ${ }^{1}$ Pediatrics and ${ }^{2}$ Pathology, Busan Paik Hospital, Inje University College of Medicine, Busan, Korea
}

\begin{abstract}
Hereditary spherocytosis is the most common hereditary red blood cell membrane disorder. It results from a deficiency in certain proteins that are part of the red blood cell membrane cytoskeleton. We report a case of adrenal myelolipoma in a 23-yearold patient with hereditary spherocytosis. She was diagnosed with hereditary spherocytosis at 7 months of age. As she grew older, hemoglobin level was low, so splenectomy was recommended, but continuous follow up was not possible due to the circumstances of the patient, so the splenectomy was delayed. Adrenal myelolipoma was discovered incidentally at the age of 23 with abdominal pain and cholecystitis with gallstones at the time. Myelolipoma is a benign tumor of the mesenchymal origin; its etiology remains unclear. Myelolipoma is composed of adipose and hematopoietic tissues and mainly arises from adrenal tissues. The mass is often detected during routine radiologic examinations because myelolipoma is usually asymptomatic and not generally associated with hematologic diseases. The prevalence of myelolipoma appears to be increasing due to the increased use of imaging modalities. The association of myelolipoma with hereditary spherocytosis has rarely been reported in the literature. To our best knowledge, this is the first report of adrenal myelolipoma associated with hereditary spherocytosis in the Korean population.
\end{abstract}

Key Words: Adrenal myelolipoma, Hereditary spherocytosis, Adrenal mass
pISSN 2233-5250 / elSSN 2233-4580 https://doi.org/10.15264/cpho.2021.28.2.98 Clin Pediatr Hematol Oncol 2021;28:98 102

Received on September 16, 2021 Revised on October 6, 2021 Accepted on October 15, 2021

Corresponding Author: Ji Kyoung Park Department of Pediatrics, Busan Paik Hospital, Inje University College of Medicine, Bokji-ro 75, Busanjin-gu, Busan 47392, Korea Tel: $+82-51-890-6972$ Fax: +82-51-895-7785 E-mail: pjk4285@hanmail.net ORCID ID: orcid.org/0000-0002-8241-2302

\section{Introduction}

Hereditary spherocytosis is the most common hereditary hemolytic anemia. Hereditary spherocytosis is caused by a defect in a cytoskeletal protein, spectrin, or a protein that contributes to the attachment of spectrin to the plasma membrane.This disorder results in osmotically vulnerable spheroid cells selectively trapped in the spleen [1].

Myelolipoma is a benign tumor of the mesenchymal origin; its etiology is unknown [2]. Myelolipoma, which consists of adipose and hematopoietic tissues, mainly occurs in adrenal gland tissue [3]. Adipose tissue arises from mesenchymal stem cells in the vascular wall of stromal fat in the adrenal cortex by certain stimuli. When adipocytes differentiate and mature, they cause inflammation and stimulate the adrenal cortex to release factors or substances that prompt circulating hematopoietic progenitor cells to settle and differentiate [4,5].

Because myelolipomas are usually asymptomatic and not associated with blood disorders, they can be found during radiographic examination [5]. Some reported symptoms include flank pain, abdominal discomfort, and hematuria $[2,6]$.

Autopsy or imaging modalities such as ultrasonography, computed tomography (CT), and magnetic resonance imaging (MRI) are helpful in diagnosing myeloli- 
poma when a person with nonspecific symptoms undergoes these examinations incidentally for other reasons $[7,8]$. The prevalence of myelolipoma appears to be increasing due to the increasing use of imaging technology [3,5]. Adrenal myelolipomas comprise $6-16 \%$ of adrenal incidentalomas and are the second most common cause after adrenal adenomas. They have an approximate autopsy prevalence of 0.08 to $0.2 \%$ [9]. The association of myelolipoma with hereditary spherocytosis has rarely been reported in the literature. Two cases have been reported over the world. The first case was reported 67-year-old woman with hereditary spherocytosis in Japan in 1996. She was diagnosed with a urinary tract infection and accidentally discovered a tumor in the adrenal myeololipoma while undergoing an examination [7]. The second case reported in Morocco in 2019 was a 36-year-old male hereditary spherocytosis, who had back pain and aderenal myelolipoma was found incidentally during an examination [2]. This is the first report of adrenal myelolipoma associated with hereditary spherocytosis in the Korean population.

\section{Case Report}

This is a case of adrenal myelolipoma associated with hereditary spherocytosis in a 23-year-old patient. Incidentally, CT revealed an adrenal mass, which was diagnosed as myelolipoma, and surgical excision was performed to remove the mass.
She was diagnosed with hereditary spherocytosis at 7 months of age. A relevant family history was noted, i.e., the patient's father and brother had hereditary spherocytosis. At 3 days of age, an exchange transfusion was performed for the patient due to neonatal hyperbilirubinemia.

At 5 years of age, the patient was admitted to the hospital on account of aplastic crisis with tonsillitis. Upon physical examination, she exhibited anemic conjunctivae, icteric sclerae, enlarged tonsil and splenomegaly. Laboratory findings were as follows: white blood cell

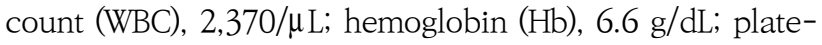
let count, 30,000/ $\mathrm{L}$; mean corpuscular volume (MCV), $85.3 \mathrm{fL}$; mean corpscular hemoglobin (MCH), $28.6 \mathrm{pg}$; mean corpscular hemoglobin concentration (MCHC), $33.5 \mathrm{~g} / \mathrm{dL}$; reticulocyte count, $0.2 \%$; corrected reticulocyte, $0.1 \%$; total bilirubin (TB), $6.1 \mathrm{mg} / \mathrm{dL}$; direct bilirubin (DB), 0.9 $\mathrm{mg} / \mathrm{dL}$; and lactate dehydrogenase (LDH), $315 \mathrm{U} / \mathrm{L}$. We had mentioned to the patient's guardians that regular evaluation will be needed; however, follow- up examinations were not undertaken for the patient.

She was admitted again when she was 16 years old on account of tonsillitis and low level of hemoglobin. On physical examination, anemic conjunctivae, icteric sclerae, splenomegaly and jaundice were noted. Laboratory findings were as follows: $\mathrm{Hb}, 5.7 \mathrm{~g} / \mathrm{dL} ; \mathrm{MCV}, 96.0 \mathrm{fL} ; \mathrm{MCH}$, 28.5 pg; MCHC, $29.7 \mathrm{~g} / \mathrm{dL}$; reticulocyte count, 10.6\%; corrected reticulocyte, 5.3\%; TB, $3.5 \mathrm{mg} / \mathrm{dL} ; \mathrm{DB}, 0.6 \mathrm{mg} / \mathrm{dL}$; and LDH, 322 U/L. Abdominal ultrasonography demon-
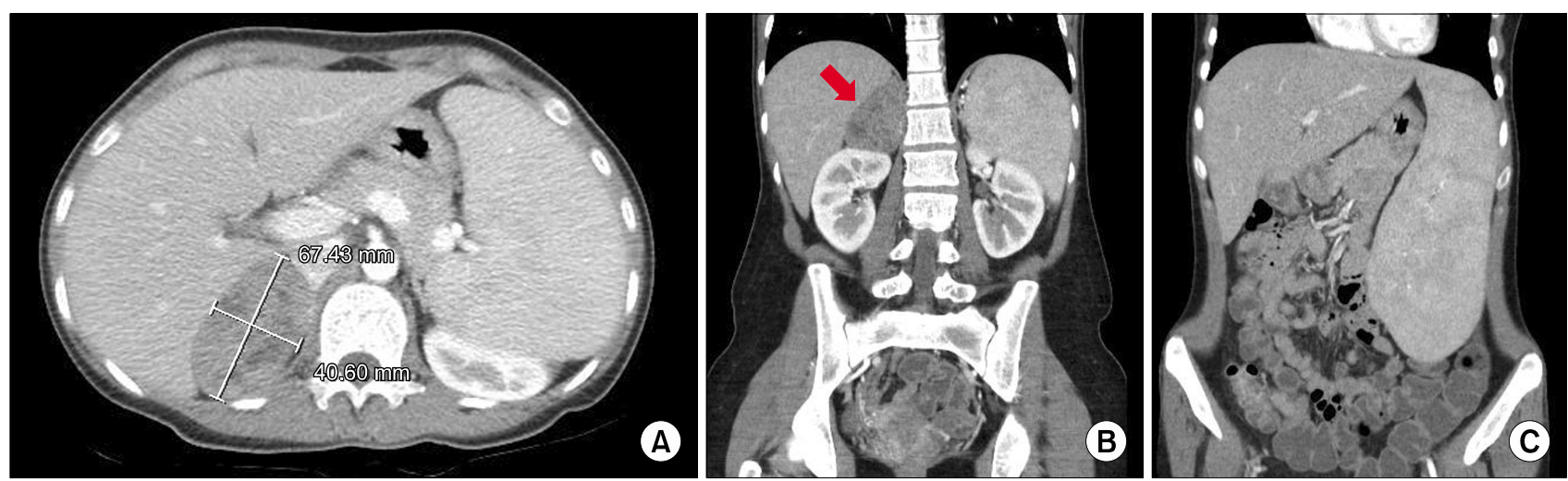

Fig. 1 Abdominal CT findings. (A) A $67 \times 41 \mathrm{~mm}$ sized mass was seen in right adrenal gland. (B) Right adrenal mass (arrow) on coronal view. (C) An enlarged spleen was found. 
strated nonspecific splenomegaly ( $28 \mathrm{~cm}$ in length) and two gallbladder stones without cholecystitis. Splenectomy was considered as a treatment option for hemolytic anemia, and follow-up evaluation and observation were necessary to prepare the patient for the surgery. She was vaccinated against Hemophilus influenza type b, pneumococcus, and meningococcus. However, the follow-up evaluation was not undertaken.

At 19 years of age, she was treated for anemia. Anemic conjunctivae, icteric sclerae, splenomegaly and jaundice were noted. Laboratory findings were as follows: $\mathrm{Hb}, 5.6$ g/dL; MCV, 88.0 fL; MCH, 30.6 pg; MCHC, 34.8 g/dL; reticulocyte count, 16.2\%; corrected reticulocyte, 6.2\%; TB, $5.2 \mathrm{mg} / \mathrm{dL} ; \mathrm{DB}, 0.7 \mathrm{mg} / \mathrm{dL}$; and LDH, $399 \mathrm{U} / \mathrm{L}$. Splenectomy was planned, but the patient and her family did not agree for surgical management and follow-up evaluation was not undertaken.

The patient visited with abdominal pain at 23 years of age. On physical examination, anemic conjunctivae, icteric sclerae, splenomegaly and jaundice were observed. Laboratory findings were as follows: $\mathrm{Hb}, 9.7 \mathrm{~g} / \mathrm{dL} ; \mathrm{MCV}$, 94.9 fL; MCH, 33.2 pg; MCHC, 35.0 g/dL; reticulocyte count, 22.9\%; corrected reticulocyte, 15.1\%; TB, $5.9 \mathrm{mg} / \mathrm{dL}$; DB, $0.6 \mathrm{mg} / \mathrm{dL}$; and LDH, $356 \mathrm{U} / \mathrm{L}$. No other underlying diseases such as diabetes or hypertension were identified and endocrine test did not show any hormonal activity in the tumor. Abdominal CT revealed an enlarged spleen, multiple gallstones, and a right adrenal mass. The size of the adrenal mass was $6.7 \times 4.1 \mathrm{~cm}$ (Fig. 1). The abdominal pain could have been a symptom of either the adrenal mass or cholecystitis; therefore, adrenalectomy was planned. Open splenectomy, cholecystectomy, and right adrenalectomy were performed. The adrenal mass weighed $72.3 \mathrm{~g}$ and measured $6.5 \times 5.5 \times 3.8 \mathrm{~cm}$. Histologically, adrenal myelolipoma was diagnosed (Fig. 2).

Table 1 shows the blood test results at the time the patient was hospitalized (Table 1). Upon follow-up, the $\mathrm{Hb}$
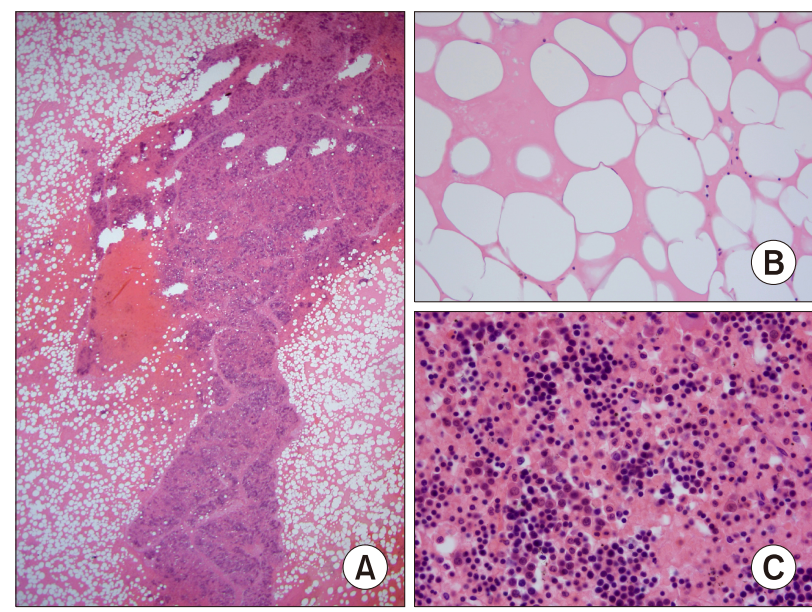

Fig. 2. Histopathological findings. (A) In low power view (hematoxylin-eosin stain, scanning view), hemorrhage and two components with different cellularity are seen in the tumor. (B) Hypocellular areas show proliferation of mature adipose tissue (hematoxylin-eosin stain, $\times 200$ ). (C) Hypercellular areas show hematopoietic cells of varying lineages (hematoxylin-eosin stain, $\times 400)$.

Table 1. Laboratory data of patient

\begin{tabular}{lccccc}
\hline & $5 \mathrm{yr}$ & $16 \mathrm{yr}$ & $19 \mathrm{yr}$ & \multicolumn{2}{c}{$23 \mathrm{yr}$} \\
\cline { 5 - 6 } & & & & \\
Hemoglobin $(\mathrm{g} / \mathrm{dL})$ & 6.6 & 5.7 & 5.6 & 9.7 & 13.9 \\
$\mathrm{MCV}$ (fL) & 85.3 & 96.0 & 88.0 & 94.9 & 89.0 \\
$\mathrm{MCH}(\mathrm{pg})$ & 28.6 & 28.5 & 30.6 & 33.2 & 30.6 \\
$\mathrm{MCHC}(\mathrm{g} / \mathrm{dL})$ & 33.5 & 29.7 & 34.8 & 35.0 & 34.4 \\
Reticulocyte count (\%) & 0.2 & 10.6 & 16.2 & 22.9 & 2.3 \\
Corrected reticulocyte (\%) & 0.1 & 5.3 & 6.2 & 15.1 & 2.2 \\
Total bilirubin (mg/dL) & 6.1 & 3.5 & 5.2 & 5.9 & 0.8 \\
Direct bilirubin (mg/dL) & 0.9 & 0.6 & 0.7 & 0.6 & 0.3 \\
LDH (U/L) & 315 & 322 & 399 & 356 & 128
\end{tabular}

MCV, mean corpuscular volume; $\mathrm{MCH}$, mean corpscular hemoglobin; $\mathrm{MCHC}$, mean corpscular hemoglobin concentration; $\mathrm{LDH}$, lactate dehydrogenase. 
level was noted to be restored to $13.9 \mathrm{~g} / \mathrm{dL}$ and the symptoms of anemia resolved. Laboratory findings were as follows: MCV, $89.0 \mathrm{fL} ; \mathrm{MCH}, 30.6 \mathrm{pg}$; MCHC, $34.4 \mathrm{~g} / \mathrm{dL}$; reticulocyte count, 2.3\%; corrected reticulocyte, 2.2\%; TB, $0.8 \mathrm{mg} / \mathrm{dL}$; DB, $0.3 \mathrm{mg} / \mathrm{dL}$; and LDH, $128 \mathrm{U} / \mathrm{L}$. There were no complaints of discomfort after surgery.

\section{Discussion}

Hereditary spherocytosis is the most common hereditary red blood cell membrane disorder, affecting 1 in 2,000 to 3,000 people [10]. It is inherited mainly as an autosomal dominant inheritance. Hereditary spherocytosis results from a deficiency in certain proteins that are part of the red blood cell membrane cytoskeleton [11]. Anemia, jaundice, and enlarged spleen are common symptoms because spheroid cells are easily destroyed by macrophages in the spleen [12].

Myelolipoma, composed of adipose and hematopoietic tissues, is a benign tumor of the mesenchymal origin, whose etiology remains unclear [2]. The mass is mostly observed during radiologic examinations because myelolipoma is usually asymptomatic and not generally associated with hematologic diseases. Some reported symptoms include flank pain, abdominal discomfort, and hematuria [2,6].

Diagnosis of myelolipoma is usually incidental and made during imaging studies (such as ultrasonography, MRI and CT) done for other symptoms unrelated to adrenal disease $[4-9,13]$. The prevalence of myelolipoma appears to be increasing due to the increased use of imaging modalities [3,5].

Myelolipoma could be caused by the following: 1) metaplasia of cortical cells of mesenchymal origin, 2) degenerative processes in differentiated cortical cells, and 3) myeloadipose structures resulting from hyperplasia of myeloid cells, known as choristoma theory. According to the choristoma theory, the misplacement of hematopoietic cells occurs during embryogenesis [2,7]. Although the adrenal myelolipoma in this case may have been incidentally associated with hereditary spherocytosis, the hematopoietic stimulus due to severe hemolysis in spher- ocytosis might induce extramedullary hematopoiesis in the adrenal gland.

Myelolipoma that is symptomatic or larger than $7 \mathrm{~cm}$ should be surgically resected since spontaneous rupture of the mass and the resulting hemorrhage could be life threatening [2,5]. Regular monitoring is recommended for asymptomatic tumors and those $<5 \mathrm{~cm}$ in diameter [5].

In the present case, adrenalectomy was performed because the mass was approximately $7 \mathrm{~cm}$, and it was uncertain whether the tumor was the cause of the abdominal pain. Growth of the mass, and symptoms such as abdominal discomfort, hematuria, and flank pain could indicate surgical treatment. In this case, splenectomy, cholecystectomy, and right adrenalectomy were performed because of the complaint of abdominal pain [3,14].

In conclusion, we report the case of a 23-year-old patient with hereditary spherocytosis who was diagnosed with myelolipoma. This is the first report of the adrenal myelolipoma associated with hereditary spherocytosis in the Korean population.

\section{Conflict of Interest Statement}

The authors have no conflict of interest to declare.

\section{References}

1. Park ES, Jung HL, Kim HJ, et al. Hereditary hemolytic anemia in Korea from 2007 to 2011: A study by the Korean Hereditary Hemolytic Anemia Working Party of the Korean Society of Hematology. Blood Res 2013;48:211-6.

2. Chakir Y, Graiouid EM, Issam J, Dakir M, Debbagh A, Aboutaieb R. Adrenal myelolipoma associated with spherocytosis: an extremely rare case. Case Reports in Clinical Medicin 2019;8:281-4.

3. Decmann Á, Perge P, Tóth M, Igaz P. Adrenal myelolipoma: a comprehensive review. Endocrine 2018;59:7-15.

4. Nabi J, Rafiq D, Authoy FN, Sofi GN. Incidental detection of adrenal myelolipoma: a case report and review of literature. Case Rep Urol 2013;2013:789481.

5. Dieckmann KP, Hamm B, Pickartz H, Jonas D, Bauer HW. Adrenal myelolipoma: clinical, radiologic, and histologic features. Urology 1987;29:1-8.

6. Feng C, Jiang H, Ding Q, Wen H. Adrenal myelolipoma: a mingle of progenitor cells? Med Hypotheses 2013;80:819-22. 
7. Sekido N, Kawai K, Takeshima H, Uchida K, Akaza H, Koiso $\mathrm{K}$. Adrenal myelolipoma associated with hereditary spherocytosis. Int J Urol 1996;3:61-3.

8. Settakorn J, Sirivanichai C, Rangdaeng S, Chaiwun B. Fineneedle aspiration cytology of adrenal myelolipoma: case report and review of the literature. Diagn Cytopathol 1999;21: 409-12.

9. Maria R, Hassam Z, Vishnu V. Adrenal myelolipoma. In: StatPearls. StatPearls Publishing, Treasure Island (FL) 2020. StatPearls Publishing LLC, 2020.

10. Da Costa L, Galimand J, Fenneteau O, Mohandas N. Hereditary spherocytosis, elliptocytosis, and other red cell membrane disorders. Blood Rev 2013;27:167-78.
11. Jin $\mathrm{H}$, Lee J, Ju H, et al. A case of hereditary spherocytosis initially manifested as an aplastic crisis caused by parvovirus B19 infection. Clin Pediatr Hematol Oncol 2020;27;120-3.

12. Bolton-Maggs PH, Langer JC, Iolascon A, Tittensor P, King MJ; General Haematology Task Force of the British Committee for Standards in Haematology. Guidelines for the diagnosis and management of hereditary spherocytosis--2011 update. Br J Haematol 2012;156:37-49.

13. Kenney PJ, Wagner BJ, Rao P, Heffess CS. Myelolipoma: CT and pathologic features. Radiology 1998;208:87-95.

14. Yamashita S, Ito K, Furushima K, Fukushima J, Kameyama S, Harihara Y. Laparoscopic versus open adrenalectomy for adrenal myelolipoma. Ann Med Surg (Lond) 2014;3:34-8. 